\title{
A questionnaire survey regarding the support needed by Yogo teachers to take care of students suspected of having eating disorders (second report)
}

Kaoru Seike ${ }^{1,2^{*}}$, Michiko Nakazato ${ }^{1,2}$, Hisashi Hanazawa ${ }^{2,3}$, Toshiyuki Ohtani ${ }^{2,4}$, Tomihisa Niitsu ${ }^{5}$, Shin-ichi Ishikawa ${ }^{6,7}$, Atsuko Ayabe ${ }^{8}$, Ryoko Otani ${ }^{8}$, Kentaro Kawabe ${ }^{9,10}$, Fumie Horiuchi ${ }^{9,10}$, Shizuo Takamiya ${ }^{6,11}$ and Ryoichi Sakuta ${ }^{8}$

\begin{abstract}
Background: The lowering of the age of onset and chronicity have been key problems related to eating disorders (EDs). As the proportion of teens in the estimated onset ages has increased, it has become important to detect students with EDs and to clarify how they can be supported. Though epidemiological surveys of Yogo teachers (school nurse/health science teachers) have been conducted to inquire about the number of such students, none of these were done according to ED type based on DSM-5. Thus, we conducted a wide area survey in Japan with the goal of proposing a better framework of support for Yogo teachers in their efforts to care for students with EDs.

Methods: A questionnaire survey organized by ED type (based on DSM-5) was administered to Yogo teachers working at elementary/junior high/senior high/special needs schools in four prefectures of Japan in 2015, and 1,886 responses were obtained. Based on the results, the encounter rates (the proportion of Yogo teachers who had encountered a student with an ED) were calculated, and factors that could affect the rates were examined by logistic regression analysis.

Results: The order of the encounter rates of the ED types was as follows: Anorexia Nervosa (AN) $>$ Bulimia Nervosa $(B N)>$ Avoidant/Restrictive Food Intake Disorder (ARFID) > Binge Eating Disorder (BED) > Others. The factors significantly affecting the rates were "location, school type, number of students, experience years, and AN knowledge" for AN, "school type, experience years, and BN knowledge" for BN, "school type, experience years, and BED knowledge" for BED, "location, experience years, and ARFID knowledge" for ARFID, and "school type, experience years, and Others knowledge" for Others.

Conclusions: Because the encounter rate of AN was the highest, providing support for AN would be the most effective. Moreover, one factor that affected the encounter rate of all ED types was ED knowledge. In addition to this, senior high schools had the highest encounter rates for AN, BN and BED, and special needs schools had the highest rates for Others. These findings imply that, in order to detect and support ED students at an early stage, it is necessary to offer knowledge of the most prevalent ED types to Yogo teachers at the corresponding school type.
\end{abstract}

Keywords: DSM-5, Eating disorder, Support, Surveillance, Yogo teacher

\footnotetext{
* Correspondence: funfunfun@sgr.e-catv.ne.jp

'United Graduate School of Child Development, Osaka University, 2

Yamadaoka, Suita-city, Osaka Prefecture 565-0871, Japan

${ }^{2}$ Research Center for Child Mental Development Chiba University, 1-8-1

Inohana, Chuo-ku, Chiba-city, Chiba Prefecture 260-8670, Japan

Full list of author information is available at the end of the article
} 


\section{Background}

The lowering of the age of onset and chronicity have been found in recent years to be key problems related to eating disorders (EDs) [1-9]. Children with EDs are likely to fall into physical crises and develop growth disorders [10-13]. It is necessary to diagnose them and intervene at an early stage. Children with EDs, especially Anorexia Nervosa (AN), strongly resist treatment, and often do not visit medical institutions. Therefore, actual condition surveys are believed to be necessary. Moreover, it is important to identify students suspected of having EDs early and to clarify the way they are supported in school, because the proportion of teens at the estimated onset age of ED has increased year by year [14].

It is important to determine how many ED students are present in school in order to provide early support. Although school physicians do medical check-ups and recommend that students suspected of having EDs visit medical institutions based on Japanese law, half to one-third of students with AN do not follow the advice [15]. Therefore, school staff members have been a focus of attention in recent years, as they are in the best position to identify the early warning signs of EDs and to support ED students [16]. Yogo teachers are unique teachers in Japan. They not only take care of students in their capacity as school nurses, but also are in charge of health education. They stay at school on weekdays, teach courses on adolescent health and have contact with parents. They are not required to have nursing licenses, although some of them do [15]. Actually, epidemiological surveys of Yogo teachers have achieved fruitful results in recent years, and many of them reported the lowering of the age of onset of EDs [17-19].

While many epidemiological actual condition surveys of AN have been conducted, surveys of other ED types have rarely been done in Japan [18] (although some have been done outside Japan [20-26]). Moreover, all of the Japanese studies were based on the diagnostic criteria in DSM-IV [15, 17-19], and no survey by ED type has been done based on the new diagnostic criteria in DSM-5.

The ED types described in DSM-5 are AN, Bulimia Nervosa (BN), Binge Eating Disorder (BED), Avoidant/ Restrictive Food Intake Disorder (ARFID), and other types of EDs such as rumination disorder or pica (Others).

The American Psychiatric Association revised the DSM diagnosis criteria in 2013, and "Eating Disorders" and "Feeding and Eating Disorders in Infancy or Early Childhood" in DSM-IV were integrated into a new diagnosis category, "Eating Behavior Disorders and Eating Disorders." This change can be attributed to the fact that there was no need to separate infancy or early childhood from other ages, as it was widely recognized that EDs, previously believed to emerge mainly in infancy or early childhood, actually emerged at other ages too. In addition, the prevalence rates of EDs were reported to be higher in DSM-5 than DSM-IV-TR, for DSM-5 has an increased number of symptom names and more flexible diagnostic criteria [22-33]. These facts mean that a new survey by ED type based on DSM-5 is necessary.

Our previous study surveyed the encounter rate to effectively support Yogo teachers in giving early support to students with EDs [34]. However, the results of that study could be biased since the survey subjects were limited to Chiba prefecture, Japan. Moreover, our results were problematic in that the confidence intervals of the estimated proportions were long, owing to the small sample sizes for special needs schools and Others. (Special needs schools are institutes for educating children flexibly according to their conditions of dysfunction.)

In order to solve these problems, we chose samples from a wider area of Japan and surveyed the encounter rate by ED type. In addition, we surveyed for factors that could affect the rates in order to enhance the effectiveness of support for children with EDs. In other words, our objectives were to conduct a questionnaire survey of Yogo teachers in four prefectures, calculate the encounter rate by ED type (based on DSM-5), and examine the relations between the rates and location, school type, number of students, years of experience as a Yogo teacher, nursing experience, and ED knowledge.

\section{Methods}

\section{Survey participants}

The survey participants were Yogo teachers working at elementary, junior high, senior high, and special needs schools in Chiba prefecture, Saitama prefecture, Hyogo prefecture, and Ehime prefecture.

\section{Demographics of the prefectures}

Chiba, Saitama, Hyogo and Ehime are administrative divisions (prefectures) of Japan. Chiba and Saitama, prefectures in the Tokyo metropolitan area, had population densities of 1,202 and 1,906 people $/ \mathrm{km}^{2}$, respectively, at the time of the study. Hyogo, a prefecture located in the Osaka metropolitan area, had 660 people $/ \mathrm{km}^{2}$. Ehime, a prefecture located to the west of Osaka, had 246 people/ $\mathrm{km}^{2}$. There are three government-ordinance-designated cities; Chiba, Saitama, and Kobe; - in these three prefectures. A government-ordinance-designated city is a city designated under Article 252, Section 19 of the Local Autonomy Law, and is a regional core with a population of more than 0.5 million that can be regarded as an urban area (Fig. 1). We classified the areas Yogo teachers worked in as "government-ordinance-designated cities" and "other areas". Because there are no cities larger than government-ordinance-designated cities in these prefectures, "government-ordinancedesignated cities" and "other areas" are roughly equal to "urban" and "rural" areas. 


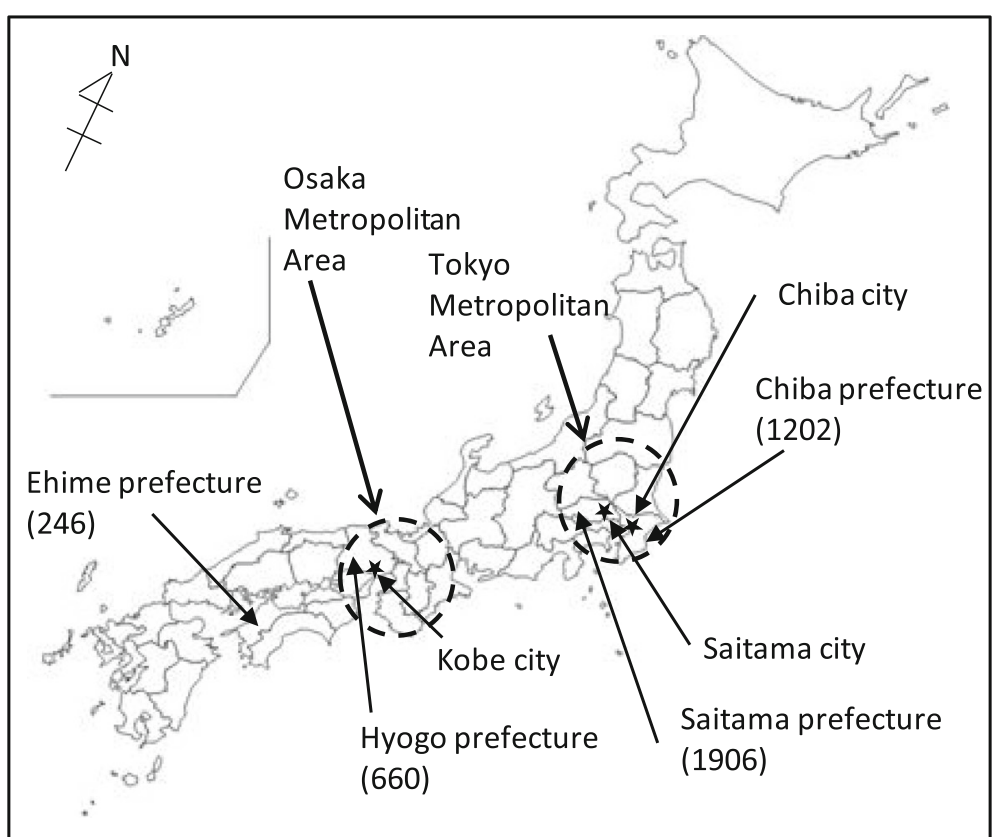

Fig. 1 Characteristics of survey areas. Note) Population densities were calculated from data by [42] and [43].

government-ordinance-designated city

\section{Study procedures}

The questionnaire used was developed by an early detection working group committee. It consists of sections asking about the attributes of Yogo teachers, the features of their schools, and their experience encountering students with an ED, as well as a free description section for the respondents and an explanation of DSM-5.

The attribute section asked about the age, gender, nursing experience, years of experience as a Yogo teacher, and school type (elementary/junior high/senior high/special needs school). The section on the features of the school asked about the gender type (boys'/girls'/ coeducational school), the number of students, and the location of the school she/he worked at. The section on the respondent's knowledge of each ED type asked about their amount of knowledge, using a four-point scale (know well/know roughly/do not know much/do not know anything). The encounter rate section asked if the respondent had encountered students with an ED, by ED type (yes/no). In the free description section, the respondent could freely write impressions or requests regarding the survey. The explanation of DSM-5 described each ED type based on the DSM-5 diagnosis criteria; this section was added because not all Yogo teachers were familiar with these new criteria.

In Chiba prefecture, the questionnaires were distributed during a Yogo teacher seminar. In the other prefectures, they were mailed to elementary/junior high/senior high/special needs schools and collected by mail.
The results for the four prefectures were combined, and two kinds of analyses were conducted to fulfill our objectives.

1) The proportion of Yogo teachers who had encountered students with the various ED (encounter rate). (The encounter rate for each type of ED was calculated by dividing the number of Yogo teachers who had encountered each type by the total number of Yogo teachers who submitted the survey. Note that the encounter rate is not a prevalence rate, but the proportion of Yogo teachers who had the experience of taking care of or meeting students with EDs.)

2) Logistic regression analyses were performed with location, school type, number of students, years of experience as a Yogo teacher, nurse experience, and knowledge of ED as explanatory variables and experience encountering students with the various ED (yes/no) as a response variable.

Note that the total number of responses includes missing values. The statistical analysis software SPSS Ver. 21.0 (IBM, Tokyo, Japan) and the statistical power analysis software G*POWER Ver. 3.1.9.2 (University of Dusseldorf, Germany) were used for the analyses.

\section{Results and discussion}

\section{Demographics of participants}

The questionnaire surveys were conducted in 2015. First, for Chiba prefecture, a survey of 1,272 Yogo 
teachers was done at a Chiba prefecture Yogo teacher seminar in January. For the other prefectures, questionnaires were sent to the schools (614 in Hyogo in February, 492 in Ehime in February, and 1,301 in Saitama in June).

For Chiba, 661 responses were obtained (the effective response rate was $52.0 \%$ ). For Hyogo, 358 responses were received (58.3\%), Ehime had $362(73.6 \%)$ and Saitama had 503 (38.7\%). Combining these, the total sample size was 1,886 .

G*POWER was used to verify the appropriateness of this sample size. By assuming the test method to be twosided, the distribution to be normal, the significance level to be .05 , the test power to be .80 , and the odds ratio to be 1.3 in the logistic regression analysis, the required sample size was calculated to be 721 . Moreover, the previous surveys of Yogo teachers reported sample sizes of 150 [18] and 391 [19]. Therefore, we judged our sample size to be large enough.

Tables 1 and 2 show the basic statistics regarding the attributes of Yogo teachers and their amount of ED knowledge. More than half $(80.6 \%)$ worked outside

Table 1 Attributes of Yogo teachers $(n=1,886)$

\begin{tabular}{|c|c|c|c|}
\hline & & $n$ & $\%$ \\
\hline \multirow[t]{3}{*}{ Location } & $\begin{array}{l}\text { Government Ordinance } \\
\text { Designated City }\end{array}$ & 344 & 19.4 \\
\hline & Other Area & 1428 & 80.6 \\
\hline & Missing & 114 & - \\
\hline \multirow[t]{5}{*}{ School Type } & Elementary school & 1037 & 55.8 \\
\hline & Junior high school & 529 & 28.4 \\
\hline & Senior high school & 206 & 11.1 \\
\hline & Special needs school & 80 & 4.3 \\
\hline & Missing & 26 & - \\
\hline \multirow[t]{8}{*}{ Number of Students } & $1-60$ & 160 & 8.7 \\
\hline & $61-200$ & 333 & 18.2 \\
\hline & $201-400$ & 481 & 26.3 \\
\hline & $401-600$ & 375 & 20.5 \\
\hline & $601-800$ & 236 & 12.9 \\
\hline & $801-1000$ & 193 & 10.5 \\
\hline & $1001+$ & 54 & 2.9 \\
\hline & Missing & 54 & - \\
\hline \multirow[t]{5}{*}{ Years of Experience } & $1-5$ & 335 & 18.0 \\
\hline & $6-10$ & 227 & 12.2 \\
\hline & $11-20$ & 299 & 16.1 \\
\hline & $20-38$ & 999 & 53.7 \\
\hline & Missing & 26 & - \\
\hline \multirow[t]{3}{*}{ Nursing Experience } & Experienced & 149 & 8.0 \\
\hline & Not experienced & 1718 & 92.0 \\
\hline & Missing & 19 & - \\
\hline
\end{tabular}

Note: \% was calculated without missing values (effective \%) government-ordinance-designated cities (i.e., other areas) and about $19.4 \%$ worked in government-ordinancedesignated cities. More than half (56.0\%) worked at elementary schools, $28.6 \%$ at junior high schools, $11.1 \%$ at senior high schools, and $4.3 \%$ at special needs schools. Of the schools, $26.3 \%$ had $201-400$ students, $20.5 \%$ had 401-600, and 18.2 \% had 61-200. About half (53.7\%) of the Yogo teachers had 20 years or more of experience. Most (92.0 \%) of them did not have nursing experience. Most of them reported that they "know roughly" about AN, BN and BED (70.7 \%, $69.9 \%$ and $55.5 \%$, respectively), while most reported that they "do not know well" about ARFID and Others (58.8 \% and $58.9 \%$, respectively).

\section{Statistical analysis 1: encounter rates for each ED type}

The results of the four prefecture surveys were combined, and the encounter rates (the proportion of Yogo teachers who had encountered students with an ED) by ED type were calculated to be (Table 3, Fig. 2):

$$
\begin{aligned}
\operatorname{AN}(45.1 \%) & >\operatorname{BN}(14.5 \%)>\operatorname{ARFID}(13.0 \%) \\
& >\operatorname{BED}(7.8 \%)>\text { Others }(5.4 \%) .
\end{aligned}
$$

\section{Statistical analysis 2: factors affecting the encounter rate} (by ED type)

Table 4 shows the results of the logistic analyses, which were used to verify the factors affecting the encounter rate. The significant factors for AN were location $(\mathrm{OR}=1.51)$, school type $(\mathrm{OR}=2.61 \sim 6.56)$, number of students $(\mathrm{OR}=1.00)$, years of experience $(\mathrm{OR}=1.05)$, and knowledge of $\mathrm{AN}(\mathrm{OR}=2.59)$. Those for $\mathrm{BN}$ were school type $(\mathrm{OR}=3.62 \sim 15.2)$, years of experience $(\mathrm{OR}=1.04)$, and knowledge of $\mathrm{BN}(\mathrm{OR}=2.84)$. Those for BED were school type (OR $=3.03 \sim 12.8)$, years of experience $(\mathrm{OR}=1.05)$, and knowledge of BED $(\mathrm{OR}=3.35)$. Those for ARFID were location $(\mathrm{OR}=1.68)$, years of experience $(\mathrm{OR}=1.03)$, and knowledge of ARFID $(\mathrm{OR}=4.23)$. Those for Others were school type $(\mathrm{OR}=9.21)$, years of experience $(\mathrm{OR}=1.03)$, and knowledge of Others $(\mathrm{OR}=3.81)$.

\section{Discussion}

In this study, to improve the way Yogo teachers are supported in their efforts to provide early support to ED students, the encounter rates of EDs in a wide area of Japan were calculated and factors that could affect those rates were examined.

\section{Statistical Analysis 1: Encounter rates for each ED type}

The order of the encounter rates for all four school types combined was AN $>$ BN $>$ ARFID $>$ BED $>$ Others. Therefore, the order of the encounter rates for seven- to 18- 
Table 2 Amount of ED knowledge of Yogo teachers $(n=1,886)$

\begin{tabular}{|c|c|c|c|c|c|c|c|c|c|c|}
\hline \multirow[b]{2}{*}{ Amount of Knowledge } & \multicolumn{2}{|l|}{ AN } & \multicolumn{2}{|l|}{$\underline{B N}$} & \multicolumn{2}{|l|}{ BED } & \multicolumn{2}{|c|}{ ARFID } & \multicolumn{2}{|c|}{ Others } \\
\hline & $n$ & $\%$ & $n$ & $\%$ & $n$ & $\%$ & $n$ & $\%$ & $n$ & $\%$ \\
\hline Know well & 206 & 15.0 & 139 & 10.2 & 75 & 5.5 & 26 & 1.9 & 11 & 1.0 \\
\hline Know roughly & 968 & 70.7 & 955 & 69.9 & 755 & 55.5 & 325 & 23.9 & 165 & 15.0 \\
\hline Do not know well & 184 & 13.4 & 261 & 19.1 & 502 & 36.9 & 800 & 58.8 & 647 & 58.9 \\
\hline Do not know anything & 11 & 0.8 & 12 & 0.9 & 28 & 2.1 & 209 & 15.4 & 275 & 25.0 \\
\hline Missing & 517 & - & 519 & - & 526 & - & 526 & - & 788 & - \\
\hline
\end{tabular}

year-old students (in elementary/junior high/senior high/special needs schools) was believed to be the same. (Note that the order of BN and ARFID might be reversed because their confidence intervals overlapped (BN $[0.129,0.161]$, ARFID [0.115, 0.146]). In that case, the order would be AN $>$ ARFID $>$ BN $>$ BED $>$ Others).

In the comparison of our results with those of surveys done outside Japan, please note that although encounter and prevalence rates are different, no encounter rates are available from outside Japan, so we used the prevalence rate for comparison. American students aged 13-18 were interviewed face to face, and the order of prevalence rates was found to be BED > BN > AN [24]. An English medical institute surveyed children aged 10-19, and the order was found to be EDNOS > AN > BN (EDNOS: Eating Disorder Not Otherwise Specified) [20]. It was reported in a number of previous studies that the onset rates of EDNOS and BED in western Europe had increased in those years, while those of AN and BN in the United States and Europe had been constant or decreased since 1970 [20, 22, 35].

In contrast, a survey of Yogo teachers [18] regarding high school girl students found the order of prevalence rates to be $\mathrm{AN}>\mathrm{EDNOS}>\mathrm{BN}$. Although the survey methods of these studies were different from ours and we cannot definitively draw any conclusions, AN seems to be the most prevalent ED in Japan. Thus, it would be effective to provide support for AN patients here.

\section{Statistical Analysis 2: Factors affecting the encounter rate (by ED type)}

The first finding was that the factors affecting the encounter rates for all ED types were years of experience and knowledge of ED. The OR of years of experience ranged

Table 3 Encounter rates for each ED type

\begin{tabular}{lll}
\hline ED Type & $n$ & Encounter rate $(95 \% \mathrm{Cl})$ \\
\hline AN & 850 & $0.451(0.428-0.473)$ \\
BN & 274 & $0.145(0.129-0.161)$ \\
BED & 148 & $0.078(0.066-0.091)$ \\
ARFID & 246 & $0.130(0.115-0.146)$ \\
Others & 102 & $0.054(0.044-0.064)$ \\
\hline
\end{tabular}

Note: $N=1,886, n=$ number of Yogo teachers who encountered students with this type of ED from 1.03-1.05, which means that the rate increases 1.031.05 times as the years of experience increase by one year. Although this result can be interpreted as "Yogo teachers enhance their skill in finding students with EDs as their experience increases," a simpler explanation is also possible, that "the probability of encountering students with EDs increases as Yogo teachers work longer." Actually, a survey of Yogo teachers who had worked at senior high schools for more than 10 years reported that the more their years of experience, the more various types of EDs they encountered.

Secondly, the relatively high ORs (2.59-4.23) implied that the amount of knowledge affected the encounters with students with an ED. It was also reported that the proportion of emaciation (extreme thinness) decreased after Yogo teachers were supplied with training on ED prevention. These facts imply that it is necessary to offer ED training in schools to improve the early support of students with EDs.

In particular, our results showed that the ORs of ARFID and Others were over 3.5. For ARFID, the ORs of all of the school types were not significant, which means that the encounter rates of all school types did not differ much and which coincided with studies reporting that ARFID is distributed among pre-puberty children as well as very young children [36]. Thus, it can be concluded that it is necessary to educate Yogo teachers about ED in all school types.

On the other hand, for Others, only the OR of special needs schools was significant. Some studies reported cases in which pica- and rumination-related obstacles (which were included in Others) co-existed with developmental disorders [37, 38]. As special needs schools are schools for educating children with disorders, it makes sense that the encounter rate for Others is high in that school type. Thus, it can be inferred that it would be effective to support Yogo teachers at special needs schools in their provision of early support for Others students.

Thirdly, the factor that did not affect the encounter rate was "nurse experience." One survey of Yogo teachers with and without nursing licenses reported that personal effort contributed to the gathering and learning of ED information for both groups of teachers. These findings 
Table 4 Factors affecting the encounter rate (By ED type)

\begin{tabular}{|c|c|c|c|c|c|c|c|c|c|c|c|}
\hline \multirow[b]{2}{*}{ Factor } & \multirow[b]{2}{*}{ Level } & \multicolumn{2}{|l|}{ AN $(n=850)$} & \multicolumn{2}{|l|}{$\mathrm{BN}(n=274)$} & \multicolumn{2}{|l|}{$\operatorname{BED}(n=148)$} & \multicolumn{2}{|l|}{ ARFID $(n=246)$} & \multicolumn{2}{|l|}{ Others $(n=102)$} \\
\hline & & n0/n1 (\%) & $O R$ & n0/n1 (\%) & $O R$ & $\mathrm{n0/n1}(\%)$ & $O R$ & n0/n1 (\%) & $O R$ & $\mathrm{n0/n1} \mathrm{( \% )}$ & $O R$ \\
\hline \multirow[t]{2}{*}{ Location } & Other Area & 606/1325 (45.7\%) & 1.00 & 209/1208 (17.3 \%) & 1.00 & 106/1132 (9.4\%) & 1.00 & 173/1063 (16.3 \%) & 1.00 & 73/927 (7.9 \%) & 1.00 \\
\hline & $\begin{array}{l}\text { Government Ordinance } \\
\text { Designated City }\end{array}$ & 192/329 (58.4 \%) & $1.51^{*}$ & $53 / 273(19.4 \%)$ & 1.19 & 28/239 (11.7\%) & 1.20 & $63 / 241(26.1 \%)$ & $1.68^{*}$ & 26/202 (12.9 \%) & 1.55 \\
\hline \multirow[t]{4}{*}{ School Type } & Elementary school & 309/964 (32.1%) & 1.00 & 65/911 (7.1 \%) & 1.00 & $39 / 870$ (4.5 \%) & 1.00 & 130/844 (15.4 \%) & 1.00 & 45/722 (6.2 \%) & 1.00 \\
\hline & Junior high school & $337 / 494(68.2 \%)$ & $4.42^{* * *}$ & 88/386 (22.8 \%) & $3.62^{* * *}$ & 49/361 (13.6\%) & $3.03^{* * *}$ & $74 / 334(22.2 \%)$ & 1.46 & $31 / 293(10.6 \%)$ & 1.43 \\
\hline & Senior high school & 156/196 (79.6 \%) & $6.56^{* * *}$ & 98/172 (57.0 \%) & $15.2^{* * *}$ & 46/134 (34.3\%) & $12.8^{* * *}$ & $31 / 121(25.6 \%)$ & 1.82 & $7 / 93(7.5 \%)$ & 1.00 \\
\hline & Special needs school & 34/75 (45.3 \%) & $2.61^{* *}$ & $17 / 69(24.6 \%)$ & $6.79 * * *$ & $11 / 65$ (16.9\%) & $8.63^{* * *}$ & 8/61 (13.1\%) & 1.03 & 18/58 (31.0 \%) & $9.21^{* * *}$ \\
\hline Number of Students & - & & $1.00^{* * *}$ & & 1.00 & & 1.00 & & 1.00 & & 1.00 \\
\hline Years of Experience & - & & $1.05^{* * *}$ & & $1.04^{* * *}$ & & $1.05^{* * *}$ & & $1.03^{* *}$ & & $1.03^{*}$ \\
\hline \multirow[t]{2}{*}{ Nursing Experience } & no & 771/1601 (48.2 \%) & 1.00 & 239/1428 (16.7 \%) & 1.00 & 130/1333 (9.8 \%) & 1.00 & 231/1271 (18.2 \%) & 1.00 & 90/1086 (8.3 \%) & 1.00 \\
\hline & yes & $74 / 140$ (52.9\%) & 0.86 & $31 / 121$ (25.6 \%) & 0.95 & 17/106 (16.0\%) & 1.11 & 14/97 (14.4 \%) & 0.85 & 11/87 (12.6 \%) & 0.74 \\
\hline Knowledge (ED) & $1-4$ & & $2.59^{* * *}$ & & $2.84^{* * *}$ & & $3.35^{* * *}$ & & $4.23^{* * *}$ & & $3.81^{* * *}$ \\
\hline
\end{tabular}

Note: ${ }^{*} p<.05,{ }^{* *} p<.01,{ }^{* * *} p<.001$. OR: Odds Ratio. $\mathrm{n} 0 / \mathrm{n} 1=$ number of Yogo teachers who encountered ED/number of Yogo teachers = encounter rate Response variable $=$ experience encountering ED students for each ED type (yes/no) 


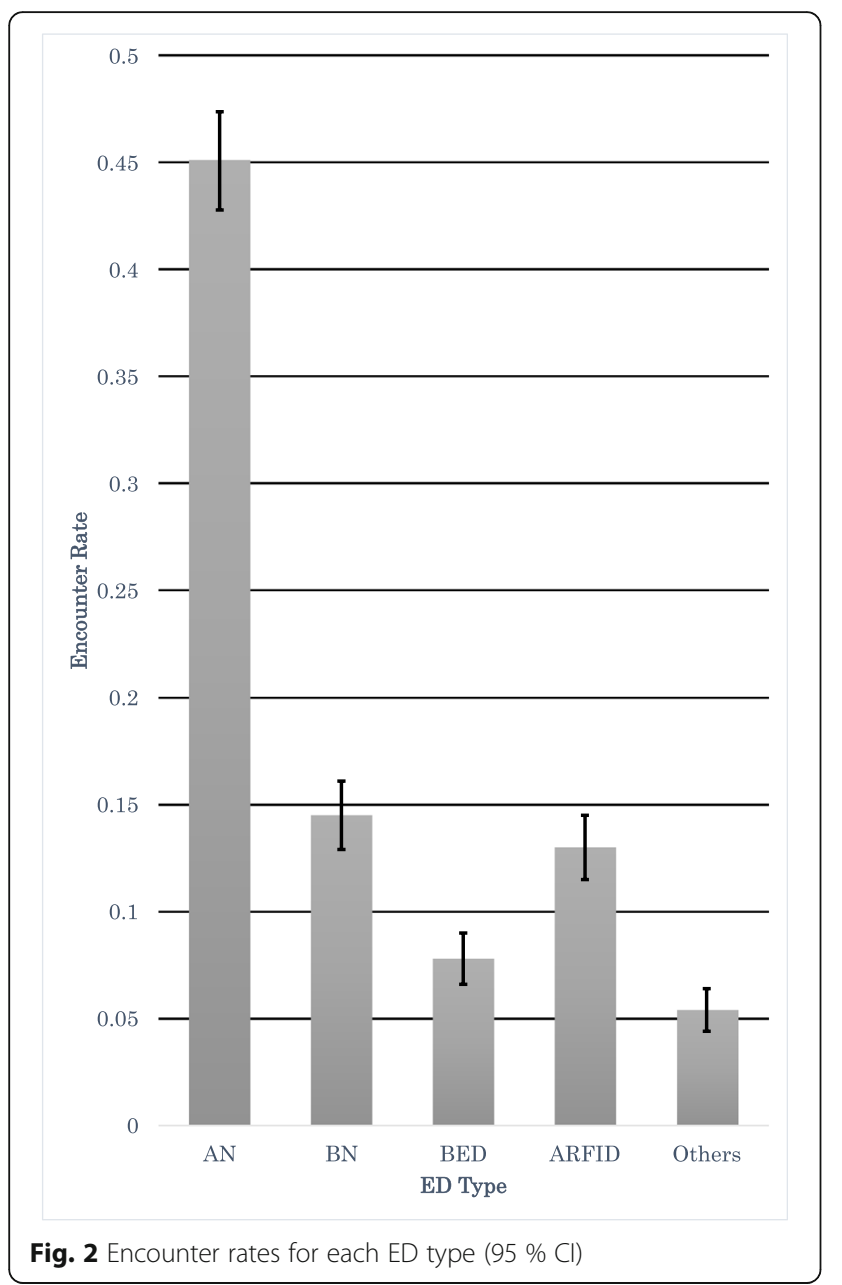

imply that nursing experience is not required to successfully provide early support for students with EDs.

For AN and ARFID, the ORs of schools in governmentordinance-designated cities ranged from 1.51-1.68, which means that the encounter rates were higher in government-ordinance-designated cities than in other areas. Because government-ordinance-designated cities can be roughly seen as urban areas and other areas as rural areas, this result was different from those of previous studies showing that the prevalence rates of urban and rural areas were almost the same [17, 18, 24, 39-41]. The use of criteria based on DSM-5 rather than DSM-IV, which was used in the previous studies, might explain this discrepancy. For example, there could have been a considerable number of students with AN, BED, or ARFID who could not be classified into the corresponding categories because of the strictness of the classification criteria of DSM-IV, but because our criteria were based on DSM-5 such students were classified correctly, making our encounter rates higher.

For school type, the ORs of all ED types except ARFID were significant. The ORs of senior high schools (with students aged from 15-18) were high (6.56-15.2) for $\mathrm{AN}, \mathrm{BN}$, and BED (the ORs of $\mathrm{BN}$ and BED were over 10), which coincided with the results of previous studies. An English survey [20] reported that the prevalence rates of 15- to 19-year-old children were higher than those of 10- to 14-year-old children for AN, BN, and EDNOS. An American survey [24] also reported that the prevalence rates for $\mathrm{BN}$ of 15 - to 16- and 17- to 18-year-old children were higher than that of 13- to 14-year-old children. These findings imply that it is necessary to support $\mathrm{BN}$ and BED in senior high schools. In comparison, the encounter rates in junior high schools were lower, but still significant (3.03-4.42). In particular, the OR of AN was high at 4.42, which implies that we should support AN beginning in junior high school.

For the number of students, only the OR of AN was significant at 1.001, which means that Yogo teachers at larger schools were more likely to encounter a student with AN. Generally speaking, teachers would be more likely to encounter various types of ED as the number of students increases. However, our results indicate that the number of students is not a significant predictor for any of the ED types except AN. The difference in the sample sizes may explain this, because the sample size of AN (850) was much bigger than those of ARFID and Others (246 and 102, respectively). The fact that the ORs of these three types were the same (1.001) also supports this explanation. (Note that the larger the sample size, the more likely it is that the OR becomes significant.)

These findings imply that it would be effective to offer ED knowledge to Yogo teachers mainly at school types with high encounter rates in order to enhance the early support of ED students.

Finally, we discuss the value of using DSM-5. In Japanese schools, a number of students have been reported to avoid school lunch, eat from their own lunch boxes, or eat their own hair (or things that are not considered edible). This suggests that ARFID and Pica are prevalent, and it would be effective to monitor the health condition of students based on the DSM- 5 criteria. In fact, descriptions of students with ARFID or Pica were common in the free-writing section of our questionnaire, in all prefectures. Therefore, a questionnaire survey based on DSM-5 is believed to be appropriate for clarifying the actual ED situation in schools in order to assist Yogo teachers in their support of students with EDs.

\section{Limitations and recommendations}

One of limitations of our study is that a diagnosis by a Yogo teacher may be less reliable than one by a doctor. Although we understand this limitation, we used the diagnosis by the Yogo teachers for two reasons: 
1) In Japan, because doctors are allowed to enter schools for school health checkups just once a year, it is difficult for them to know the daily health condition of the students. In comparison, Yogo teachers stay in the schools and witness the health condition of students on a daily basis. Moreover, they are able to obtain information about students from other teachers or students. Thus, diagnosis by Yogo teachers may to some extent be more accurate than that by a doctor.

2) Because Japanese students with EDs seldom go to medical institutions by themselves, Yogo teachers play an important role in finding them and supporting them. For this purpose, it is necessary to offer Yogo teachers information that is useful for supporting ED students, and the encounter rate is one such piece of information. Because our ultimate objective is to support Yogo teachers, we consider the subjective encounter rate to be more suitable than the objective prevalence rate, and we considered the encounter rates reported by Yogo teachers to be more suitable than those of doctors.

However, our choice created another limitation - a lack of prevalence rates. What we surveyed was the encounter rate and not the prevalence rate. That is, what we obtained was "the proportion of Yogo teachers who had encountered EDs" and not "the proportion of students with EDs." For example, there are students with EDs who are not found by Yogo teachers because the teachers do not have sufficient knowledge or the students avoid visiting the offices of the Yogo teachers. Thus, the encounter rate differs from the prevalence rate.

The prevalence rate is also useful information, and should be determined in a future study by asking students directly if they have an ED. In such a study, information such as the age and sex of the students should also be obtained, as it could contribute to better support for Yogo teachers in their early assistance for students with EDs.

Other limitations include the questionnaire distribution methods. In our survey, the questionnaire was distributed by hand at a seminar hall or by mail. This difference in methods of distribution might have led to a difference in the degree of self-exposure to the questionnaire. A single survey method should be used in the future. In addition, our sample might be biased, as most of the surveys were collected from outside government-ordinance-designated city areas, which are usually rural areas. We will need to gather samples equally from inside and outside government-ordinancedesignated cities in our future study.

\section{Conclusions}

In this study, questionnaire survey was administered to Yogo teachers at elementary/junior high/senior high/ special needs schools in a wide area of Japan regarding their rates of encounter with students having various types of ED (based on DSM-5). The encounter rates were then calculated, and factors affecting the encounter rate were examined based on the survey results. The results showed the order of encounter rates to be AN > $\mathrm{BN}>\mathrm{ARFID}>\mathrm{BED}>$ Others for students aged 7-18 (elementary/junior high/senior high/special needs schools). Because AN was found at a significantly higher rate than the other types of $E D$, our study implies that supporting AN would be effective.

One factor affecting the encounter rates of all ED types was ED knowledge. Moreover, Yogo teachers at senior high schools were most likely to encounter students with AN, BN, or BED and those at special needs schools were most likely to encounter students with Others. These findings imply that in order to identify and support students with EDs early, it is necessary to offer knowledge regarding the ED type with the highest encounter rate by school type.

\section{Abbreviations}

AN: anorexia nervosa; ARFID: avoidant/restrictive food intake disorder; BED: binge eating disorder; BN: bulimia nervosa; Cl: confidence interval; ED: eating disorder; EDNOS: Eating disorder not otherwise specified; EOED: early onset EDs; Others: pica rumination disorder, etc

\section{Acknowledgments}

We are grateful for the assistance of the Yogo teachers. We also thank Teruko Ikuno, Aya Nishizono-Maher, Tetsuya Ando, Yuki Matsumoto, Eiji Shimizu and Masaomi lyo for their assistance. This study was supported by the Japanese Ministry of Health, Labor and Welfare (research on medical treatment system of ED).

\section{Funding}

This study was not supported by any funds.

\section{Availability of data and materials}

As our data contains personal information, it cannot be shared.

\section{Authors' contributions}

$\mathrm{KS}, \mathrm{MN}, \mathrm{ST}, \mathrm{RS}$, and KK conceived and designed this study. All authors collected and collated the data. $\mathrm{KS}, \mathrm{MN}, \mathrm{HH}$, and TO carried out the study in Chiba. ST and SI carried out the study in Hyogo. RS, AA, and RO carried out the study in Saitama. KK and FH carried out the study in Ehime. KS, SI, AA, RO and FH analyzed the data. KS, MN, HH, TO, ST, and RS interpreted the findings. KS prepared the manuscript, and $\mathrm{MN}, \mathrm{HH}, \mathrm{TO}, \mathrm{ST}$, and RS reviewed the draft and final manuscript versions. All authors read and approved the final manuscript.

\section{Competing interests}

The authors declare that they have no competing interests.

\section{Consent for publication \\ Not applicable.}

\section{Ethics approval and consent to participate}

The study was approved by the Ethics Committees of Chiba University, Dokkyo Medical University Koshigaya Hospital, Nishi-Kobe Medical Center and Ehime University Hospital. We explained our research to the educational committees of Chiba, Hyogo, Ehime and Saitama prefectures and of the cities, as well as to the school principals, the head of the Yogo teacher association, and the Yogo teachers through both written and oral descriptions. All participants gave their written informed consent.

After these individuals had a sufficient understanding of our project, we conducted the survey. The questionnaire was anonymous and responses 
were kept in lockers so the identities of the respondents would not be revealed. Moreover, the questionnaire clearly stated that responding to the questionnaire was voluntary.

\section{Author details}

${ }^{1}$ United Graduate School of Child Development, Osaka University, 2 Yamadaoka, Suita-city, Osaka Prefecture 565-0871, Japan. ${ }^{2}$ Research Center for Child Mental Development Chiba University, 1-8-1 Inohana, Chuo-ku, Chiba-city, Chiba Prefecture 260-8670, Japan. ${ }^{3}$ Faculty of Education, Chiba University, 1-33 Yayoi, Inage-ku, Chiba-city, Chiba Prefecture 263-0022, Japan. ${ }^{4}$ Safety and Health Organization, Chiba University, 1-33 Yayoi, Inage-ku, Chiba-city, Chiba Prefecture 263-0022, Japan. ${ }^{5}$ Department of Psychiatry, Graduate School of Medicine, Chiba University, 1-8-1 Inohana, Chuo-ku, Chiba-city, Chiba Prefecture 260-8670, Japan. 'Department of Psychiatry, Nishi-Kobe Medical Center, Kobe, 5-7-1 Koujidai, Nishi-ku, Kobe-city, Hyogo Prefecture 651-2273, Japan. ${ }^{7}$ Kishibe Psychiatry Clinic, 1-24-1 Kishibe Minami, Suita-city, Osaka Prefecture 564-0011, Japan. ${ }^{8}$ Center for Child Development and Psychosomatic Medicine, Dokkyo Medical University Koshigaya Hospital, 2-1-50 Minami-koshigaya, Koshigaya-city, Saitama Prefecture 343-0845, Japan. ${ }^{9}$ Department of Neuropsychiatry, Ehime University Graduate School of Medicine, Shitsukawa Toon-City, Ehime Prefecture 791-0204, Japan. ${ }^{10}$ Center for Child Health, Behavior and Development, Ehime University Hospital, Shitsukawa Toon-City, Ehime Prefecture 791-0204, Japan. ${ }^{11}$ Takamiya Mental Clinic, Akashi, Marunouchi Bldg 5F, 2-5-2 Marunouchi, Akashi-city, Hyogo Prefecture 673-0016, Japan.

Received: 8 June 2016 Accepted: 21 September 2016 Published online: 29 September 2016

\section{References}

1. Lang K, Lloyd S, Khondoker M, Simic M, Treasure J, Tchanturia K. Do children and adolescents with anorexia nervosa display an inefficient cognitive processing style? PLoS One. 2015;10. doi: 10.1371/journal.pone.0131724.

2. Neumärker KJ. Mortality and sudden death in anorexia nervosa. Int J Eat Disord. 1997;21:205-12

3. Papadopoulos FC, Ekbom A, Brandt L, Ekselius L. Excess mortality, causes of death and prognostic factors in anorexia nervosa. Br J Psychiatry. 2009;194: 10-7. doi:10.1192/bjp.bp.108.054742.

4. Lang K, Dapelo MM, Khondoker M, Morris R, Surguladze S, Treasure J, et al. Exploring emotion recognition in adults and adolescents with anorexia nervosa using a body motion paradigm. Eur Eat Disord Rev. 2015;23:262-8. doi:10.1002/erv.2358.

5. Kurz S, Van Dyck Z, Dremmel D, Munsch S, Hilbert A. Early-onset restrictive eating disturbances in primary school boys and girls. Eur Child Adolesc Psychiatry. 2015;24:779-85. doi:10.1007/s00787-014-0622-z.

6. Cardi V, Corfield F, Leppanen J, Rhind C, Deriziotis S, Hadjimichalis A, et al. Emotional processing of infants displays in eating disorders. PLoS One. 2014:9. doi: 10.1371/journal.pone.0113191.

7. Kothari R, Rosinska M, Treasure J, Micali N. The early cognitive development of children at high risk of developing an eating disorder. Eur Eat Disord Rev. 2014;22:152-6. doi:10.1002/erv.2274.

8. Kelly NR, Shank LM, Bakalar JL, Tanofsky-Kraff M. Pediatric feeding and eating disorders: current state of diagnosis and treatment. Curr Psychiatry Rep. 2014;16:446. doi:10.1007/s11920-014-0446-z.

9. Nicely TA, Lane-Loney S, Masciulli E, Hollenbeak CS, Ornstein RM. Prevalence and characteristics of Avoidant/Restrictive Food Intake Disorder in a cohort of young patients in day treatment for eating disorders. J Eat Disord. 2014;2: 21. doi:10.1186/s40337-014-0021-3.

10. Micali N, Stahl D, Treasure J, Simonoff E. Childhood psychopathology in children of women with eating disorders: understanding risk mechanisms. J Child Psychol Psychiatry. 2014;55:124-34. doi:10.1111/jcpp.12112.

11. Mann AP, Accurso EC, Stiles-Shields C, Capra L, Labuschagne Z, Karnik NS, et al. Factors associated with substance use in adolescents with eating disorders. J Adolesc Health. 2014;55:182-7. doi:10.1016/j.jadohealth.

12. Harrison C, Mond J, Bentley C, Gratwick-Sarll K, Rieger E, Rodgers B. Loss of control eating with and without the undue influence of weight or shape on self-evaluation: evidence from an adolescent population. J Eat Disord. 2014; 2:31. doi:10.1186/s40337-014-0031-1.

13. Rohde P, Stice E, Marti CN. Development and predictive effects of eating disorder risk factors during adolescence: Implications for prevention efforts. Int J Eat Disord. 2015;48:187-98. doi:10.1002/eat.22270.
14. Ministry of Health, Labor and Welfare - Japan. Eating disorders. Available from: http://www.mhlw.go.jp/kokoro/speciality/detail_eat.html Accessed 19 Dec 2015.

15. Hotta M, Horikawa R, Mabe H, Yokoyama S, Sugiyama E, Yonekawa T, et al. Epidemiology of anorexia nervosa in Japanese adolescents. BioPsychoSocial Med. 2015:9:17. doi:10.1186/s13030-015-0044-2.

16. Knightsmith P, Treasure J, Schmidt U. Spotting and supporting eating disorders in school: recommendations from school staff. Health Educ Res. 2013;6:1004-13. doi:10.1093/her/cyt080

17. Komaki G, Kachi Y. Eight prefecture survey of Yogo teachers inquiring about the risk factors, early detection methods and intervention for disordered eating among Japanese teenagers. Jpn J Psychosom Med. 2005;45:707-18.

18. Suzuki HM, Ohara T, Horikawa R, Ogawa Y. The epidemiology survey of the anorexia nervosa by the questionnaire to teachers in charge of health education of high schools in Tokyo. Jpn J Psychosom Intern Med. 2013;17:81-7.

19. Karaki M, Takamiya S, Kawazoe A. The survey concerning about between eating disorder and sports from the questionnaire for staff advisers of the sports club, Yogo teachers, teachers. J Jpn Soc Psychosom Pediatr. 2014;23:271-8.

20. Micail N, Hagberg KW, Petersen I, Treasure JL. The incidence of eating disorders in the UK in 2000-2009: Findings from the General Practice Research Database. BMJ Open. 2013;3. doi:10.1136/bmjopen-2013-002646.

21. Nicholls DE, Lynn R, Viner RM. Childhood eating disorders: British national surveillance study. Br J Psychiatry. 2011;198:295-301. doi:10.1192/bjp.bp.110. 081356

22. Allen KL, Byrne SM, Oddy WH, Crosby RD. DSM-IV-TR and DSM-5 eating disorders in adolescents: prevalence, stability, and psychosocial correlates in a population-based sample of male and female adolescents. J Abnorm Psychol. 2013;122:720-32.

23. Smink FRE, Hoeken DV, Oldehinkel AJ, Hoek HW. Prevalence and severity of DSM-5 eating disorders in a community cohort of adolescents. Int Eat Disord. 2014;47:610-9.

24. Swanson SA, Crow SJ, Grange DL, Swendsen J, Merikangas KR. Prevalence and correlates of eating disorders in adolescents. Results from the national comorbidity survey replication adolescent supplement. Arch Gen Psychiatry. 2011;68:714-23.

25. Madden S, Morris A, Zurynski YA, Kohn M, Elliot EJ. Burden of eating disorders in 5-13-year-old children in Australia. Med J Aust. 2009;190:410-4.

26. Parkinson KN, Drewett RF, Couteur AS, Adamson AJ. The Gateshead Millennium Study core team: Earlier predictors of eating disorder symptoms in 9-year-old children. A longitudinal study. Appetite. 2012;59:161-7.

27. Birgegard A, Norring C, Clinton D. DSM-IV versus DSM-5: Implementation of proposed DSM-5 criteria in a large naturalistic database. Int J Eat Disord. 2012:45:353-61.

28. Goldschmidt AB, Accurso EC, O'Brien S, Kara Fitzpatrick K, Lock JD, Le Grange D. The importance of loss of control while eating in adolescents with purging disorder. Int J Eat Disord. 2016;10. doi: 10.1002/eat.22525.

29. Norris ML, Katzman DK. Change is never easy, but it is possible: Reflections on Avoidant/Restrictive Food Intake Disorder two years after its introduction in the DSM-5. J Adolesc Health. 2015;57:8-9. doi:10.1016/j.jadohealth.2015.04.021.

30. Flament MF, Henderson K, Buchholz A, Obeid N, Nguyen HN, Birmingham $\mathrm{M}$, et al. Weight status and DSM-5 diagnoses of eating disorders in adolescents from the community. J Am Acad Child Adolesc Psychiatry. 2015:54:403-11. doi:10.1016/j.jaac.2015.01.020.

31. Mancuso SG, Newton JR, Bosanac P, Rossell SL, Nesci JB, Castle DJ. Classification of eating disorders: comparison of relative prevalence rates using DSM-IV and DSM-5 criteria. Br J Psychiatry. 2015;206:519-20. doi:10. 1192/bjp.bp.113.143461.

32. Fisher M, Gonzalez M, Malizio J. Eating disorders in adolescents: how does the DSM-5 change the diagnosis? Int J Adolesc Med Health. 2015;27:437-41. doi:10.1515/ijamh-2014-0059

33. Fisher MM, Rosen DS, Ornstein RM, Mammel KA, Katzman DK, Rome ES, et al, Characteristics of Avoidant/Restrictive Food Intake Disorder in children and adolescent: a "New Disorder" in DSM-5. J Adolesc Health. 2014;55:49-52.

34. Seike K, Nakazato M, Hanazawa H, Ohtani T, Takamiya S, Sakuta R. A questionnaire survey of the type of support required by Yogo teacher to effectively manage students suspected of having an eating disorders. BioPsychoSocial Med. 2016;10:15. doi:10.1186/s13030-016-0065-5.

35. Nakai Y, Nin K, Teramukai S, Taniquchi A, Fukushima M, Wonderlich SA. Comparison of DSM-IV diagnostic criteria versus the broad categories for the diagnosis of eating disorders scheme in a Japanese sample. Eat Behav. $2013 ; 14: 330-5$ 
36. Bryant-Waugh R. Avoidant Restrictive Food Intake Disorder: An illustrative case example. Int J Eat Disord. 2013;46:420-3. doi:10.1002/eat.22093.

37. Kliebert ML, Tiger JH. Direct and distal effects of noncontingent juice on rumination exhibited by a child with autism. J Appl Behav Anal. 2011;44: 955-9.

38. Gillberg C. Are autism and anorexia nervosa related? Br J Psychiatry. 1983; 142:428.

39. Hoek HW, Bartelds Al, Bosveld JJ, Graf Y, Limpens VE, Maiwald M, et al. Impact of urbanization on detection rates of eating disorders. Am J Psychiatry. 1995;152:1272-8.

40. Mitchison D, Hay P, Slewa-Younan S, Mond J. The changing demographic profile of eating disorder behaviors in the community. BioMed Central. 2014;14:943. doi:10.1186/1471-2458-14-943.

41. Steinhausen HC, Jakobsen H, Helenius D, Munk-Jorgensen P, Strober M. A nation-wide study of the family aggregation and risk factors in anorexia nervosa over three generations. Int J Eat Disord. 2015;48:1-8.

42. Statistical Handbook of Japan October 1, 2014 Population Census. Available from: http://www.stat.go.jp/data/jinsui/2014np/ Accessed 19 Dec 2015.

43. Ministry of Land, Infrastructure, Transport and Tourism - Japan. Geospatial Information Authority of Japan. List of Japanese prefectures by area. Available from: http://www.gsi.go.jp/kihonjohochousa/kihonjohoch ousa60012.html Accessed 19 Dec 2015.

Submit your next manuscript to BioMed Central and we will help you at every step:

- We accept pre-submission inquiries

- Our selector tool helps you to find the most relevant journal

- We provide round the clock customer support

- Convenient online submission

- Thorough peer review

- Inclusion in PubMed and all major indexing services

- Maximum visibility for your research

Submit your manuscript at www.biomedcentral.com/submit
Biomed Central 